\title{
SNAPSHOT
}

\section{Hunger and climate}

Food security is an increasing concern. It has been defined by the World Health Organisation as "when all people at all times have access to sufficient, safe, nutritious food to maintain a healthy and active life". Food security can be analysed by looking at four factors: food availability; food access, including price; food utilization - the ability to metabolize and absorb nutrients; and food stability - that is, supply chain stability, which can be disrupted by extreme weather events.

Climate change will affect arable and agricultural lands. Some areas may benefit agriculturally, as a result of enhanced rainfall and carbon dioxide fertilization, but many will see productivity fall. Water availability, or excess, may disrupt the supply of food and cause health and sanitation problems. Extreme events, such as tropical storms, floods and heatwaves, can destabilize food supply. It is estimated that 100-200 million people maybe at risk of hunger as a result of climate change by 2050 . The Intergovernmental Panel on Climate Change (IPCC) reported that climate change is expected to affect all aspects of food security
(http://go.nature.com/ZYsFuZ). The tropical region, already the most vulnerable for food security, is expected to be the most adversely affected.

Food security was discussed at the recent Rio+20 meeting and has been debated in many international forums. Global leaders and decision-makers need research to inform these decisions. The UK's Met Office and the World Food Program are working together to address this issue. Researchers have created a Hunger and Climate Vulnerability Index (http://www.metoffice.gov.uk/climatechange/guide/impacts/food and http://www.wfp.org/climate-change). They have produced a global map to illustrate the vulnerability of individual countries to hunger and climate, rated from very low to very high, as well as the current percentage of populations that are undernourished. To generate the map, they used the IPCC definition of vulnerability "the relationship between the degree of climate stress on populations (exposure); the degree of responsiveness to stress (sensitivity); and the ability of populations to adjust to climate changes (adaptive

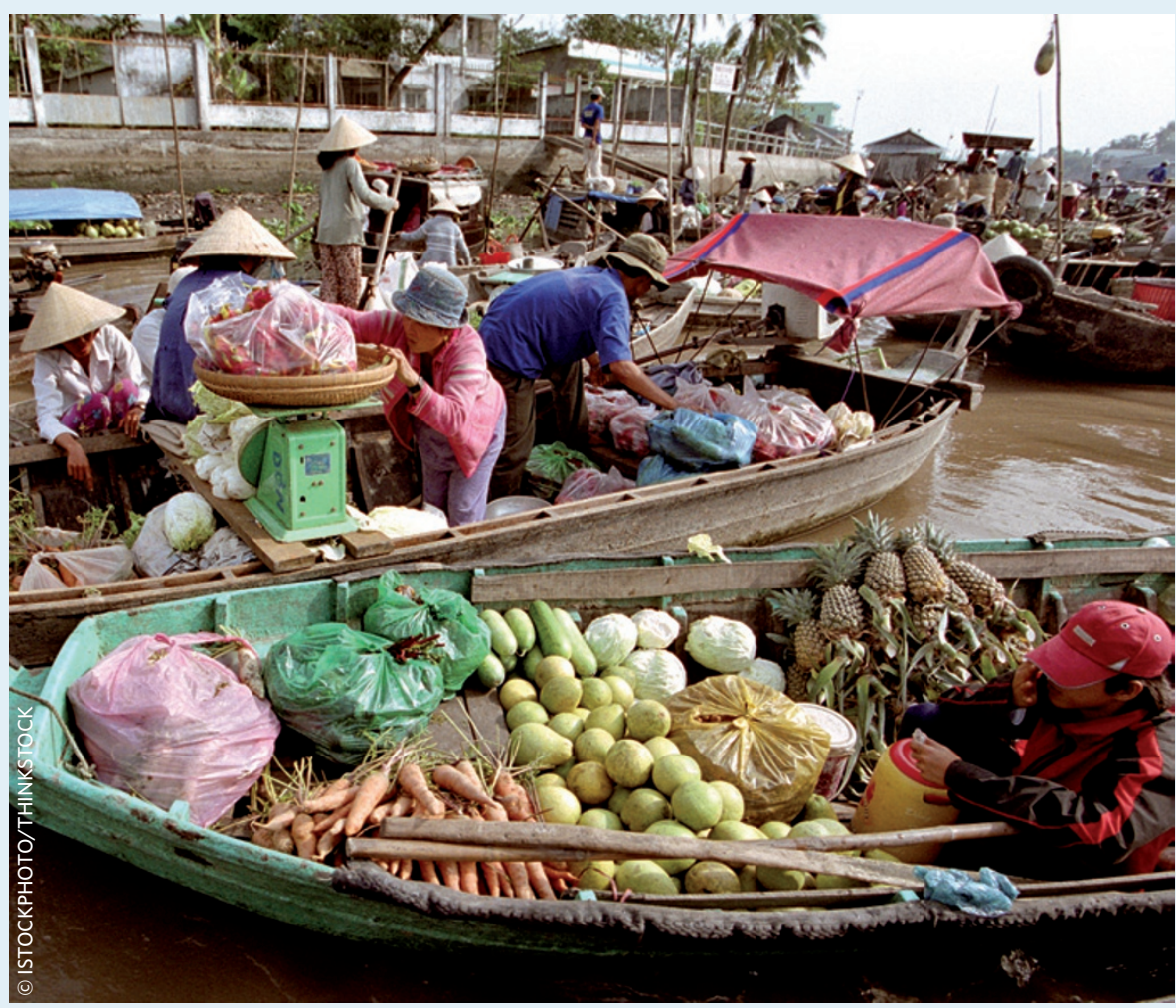

capacity)" - and 17 indicators. The indicators were chosen for their relevance to food security, to represent exposure (demographics, climate-related hazard frequency and intensity); sensitivity (agricultural and environmental profiles); and adaptive capacity (socio-economics, infrastructure and governance).

The Hunger and Climate Vulnerability Index is not the only work being undertaken to address this issue, however it is unique in the link between climate change researchers and humanitarian agencies. Other humanitarian work utilizes climate information, for example to create maps of the current food and nutrition crisis in the Sahel region, where an estimated 18.7 million people are at risk. Drought is a major factor in the region, but the situation is exacerbated by areas of armed conflict, causing displacement of people. Work by the Partnership for Maternal, Newborn \& Child Health and partners focuses on women, and children under 5 years of age. Currently almost half a billion in these categories are undernourished, and it is estimated to increase by up to $20 \%$ in the next 10 years. Linking the latest climate research with knowledge of current food security will enable risks to be identified sooner, allowing proactive measures to be taken, rather than reacting as a situation develops.

Further work to update the Index is needed as understanding of climate change effects increases. Planning for future food security needs to account for climate change, with consideration for socio-economic interactions and development, which are difficult to predict. Food security is just one issue that climate change will have an increasing effect on; this work does not take into account displacement due to climate changes or emerging conflict zones. Increasing food security in vulnerable areas may mitigate the need for migration and help prevent conflict. The Hunger and Climate Vulnerability Index is a useful tool, which can be used to help project vulnerable regions, and allow policy and decisionmakers to prepare and protect those at risk. 